\section{In Vitro Evaluation of the Efficacy of Different Over-the-Counter Products on Tooth Whitening}

Muhammet Karadas, Zeynep Yesil Duymus
Department of Restorative and Prosthodontics Dentistry, Recep Tayyip Erdoğan University, Rize, Turkey

Correspondence: Dr. Muhammet Karadas, Recep Tayyip Erdoğan University, Faculty of Dentistry, Department of Restorative Dentistry, Rize - 53100, Turkey. Tel: +90 464-222-0001. e-mail: muhammet.2005@hotmail.com
This in vitro study evaluated the whitening effect of four different over-the-counter products compared with a 10\% carbamide peroxide (CP) bleaching gel. Specimens obtained from bovine incisors were stained in a tea solution and randomly divided into six groups according to the product used $(n=10)$ : CT: conventional toothpaste (negative control); CWT: Crest 3D White toothpaste; CWR: Crest 3D White mouth rinse; CWS: Crest 3D White strips; DW: Dazzling White (paint-on gel); and OP: Opalescence PF 10\% $\mathrm{CP}$ (at-home bleaching gel, positive control). Over-the-counter products and 10\% CP were used according to the manufacturer's recommendations. Color measurements were performed according to the CIELab system using spectrophotometer after staining, and after 4 and 8 weeks of the treatment procedure. The $\Delta \mathrm{E}, \Delta \mathrm{L}, \Delta \mathrm{a}$, and $\Delta \mathrm{b}$ values were calculated. The data obtained were analyzed by repeated-measures ANOVA. Tukey's test for multiple comparisons was applied $(p<0.05)$. All groups, except CWT, were effective in tooth whitening in comparison with conventional toothpaste. There was no significant difference in tooth whitening between CWT and CT ( $p=0.93)$. CWS, DW and OP groups presented significantly higher color changes than the CWR group. DW and CWS showed similar tooth whitening to OP.
Key Words: carbamide peroxide, white strip, spectrophotometry.

\section{Introduction}

Patients have been demanding more than a healthy mouth in recent years and they increasingly want to have a perfect smile (1). Color and aesthetics of teeth is an important topic for patients, as they influence self-esteem and professional relationships (2).

The color of teeth is influenced by a combination of their intrinsic color and the presence of any extrinsic stains on tooth surface $(1,3)$. Extrinsic discoloration originates from external chromogens and is often promoted by smoking, dietary intake of tannic-rich foods and the use of certain cationic agents, such as chlorhexidine or metal salts such as tin and iron $(4,5)$. Intrinsic stains occur when chromogens are deposited within the tooth structure and are often of systemic or pulpal origin $(3,5)$. A third category of stain internalization has been defined to include those circumstances where extrinsic chromogens enter the tooth through defects in the tooth structure (5).

Patients spend large amounts of money and time to improve the appearance of teeth (6). Demand for whitening treatments has recently risen, as it comprises a conservative and simple option for the aesthetic treatment of stained teeth $(7,8)$. Whitening treatment is an effective method for restoring or lightening tooth stains with a variety of methods and systems, and fundamental vital tooth bleaching techniques can be generally classified as athome (nightguard bleaching), in-office or power bleaching (professionally administered) and over-the-counter (OTC) or mass market products (8).

OTC products appeared as a low-cost alternative to white discolored teeth without dentist supervision. Different OTC agents are available in supermarkets and pharmacies and on the Internet (9). These products generally contain lower levels of whitening agent and are self-applied to the tooth by gum shields, strips or painton brushes and commonly require twice-daily application for up to two weeks (8). All of these products contain low concentrations of carbamide peroxide (CP) or hydrogen peroxide (HP) as active agents $(2,9)$. HP or CP is capable of penetrating the tooth structure, causing a breakdown of intrinsic stains and the pigments responsible for color alteration (2). Whitening dentifrices rarely contain $\mathrm{CP}$ or HP or any other type of bleaching agent. The mechanism of action of these products is related to the large quantity of abrasives in their ingredients, removing and controlling superficial extrinsic stains $(9,10)$.

Considering the wide range of whitening agents, many patients and clinicians want to know the whitening effect of OTC products, but available information about the efficacy of these agents is restricted. Therefore, the aim of this in vitro study was to evaluate the whitening effect of four available OTC products (one whitening dentifrice, one mouth rinse, one paint-on gel and one set of strips) compared with a $10 \% \mathrm{CP}$ at-home bleaching gel. The null hypothesis was that OTC products had no effect on the color change of teeth. 


\section{Material and Methods}

Sixty bovine incisors were collected immediately after animals were sacrificed. The teeth were stored in a $0.5 \%$ chloramine-T solution after the remaining periodontal etiology was manually cleaned with hand scalers and used within 1 week of extraction. Enamel-dentin slabs (5x5 mm and 3-mm-thick) were prepared using a water-cooled diamond saw (Impect PC10, Equilam Lab Equip, Diadema, $\mathrm{SP}$, Brazil) and embedded in transparent acrylic resin to expose the enamel surface. The buccal surface of each tooth specimen was polished for $10 \mathrm{~s}$ with a prophylaxis paste, applied with a polishing brush under manual pressure on a low-speed contra angle, and then washed with distilled water for $10 \mathrm{~s}$. The prepared specimens were immersed for $24 \mathrm{~h}$ in a tea mixture prepared by brewing $3.5 \mathrm{~g}$ of black tea in $100 \mathrm{~mL}$ of boiling water for 10-12 min (Çaykur; Altınbaş Tea, Rize, Turkey). The specimens were washed in distilled water for $10 \mathrm{~s}$ and randomly divided into 6 groups $(n=10)$ according to the products used as follows: Group CT (negative control): The specimens were brushed with a conventional toothpaste (Colgate Total); Group CWT: The specimens were brushed with a whitening toothpaste (Crest 3D White toothpaste); Group CWR: The specimens were $\vec{\nabla}$ brushed with a conventional toothpaste and then immersed in whitening oral rinse for $1 \mathrm{~min}$ twice daily (Crest 3D Whiterinse); Group CWS: The specimens were brushed with a conventional toothpaste, and then a section of whitestrip (Crest 3D White strips) was applied to the specimen for 30 min twice daily for 14 days; Group DW: The specimens were brushed with a conventional toothpaste, and then a whitening gel (Dazzling White paint-on gel) was applied to specimens with a paintbrush for 10 min twice daily for 28 days; Group OP (positive control): Home bleaching gel (Opalescence PF 10\% CP) was applied to specimens for 4 $\mathrm{h}$ daily for 14 days, and the specimens were immersed in distilled water for the rest of the day (20 h).

Materials' properties, manufacturers and components are shown in Table 1. The stained specimens were brushed with electric toothbrushes (11) in daily mouth cleaning mode (Triumph 5000 D34; Oral B, Braun GmbH, Kronberg Germany) for $2 \mathrm{~min}$ (12) twice daily for 8 weeks. The brush head had a soft bristle structure and was made of nylon. The specimens were placed in a silicone mold made especially for each specimen and then were brushed with freshly prepared toothpaste mixture, which contained one part dentifrice in three parts deionized distilled water (13). The toothbrush was fixed on a steel rod with clamp and brushing was performed with a typical force of $200 \mathrm{~g}$ (12), measured with an orthodontic gauge (Correx; Haag-Streit, Koeniz, Switzerland). The toothpaste mixture was applied every $30 \mathrm{~s}$ over the tooth and specimens were washed with distilled water for $10 \mathrm{~s}$ after brushing. During testing intervals for all groups, specimens were maintained in distilled water at $37^{\circ} \mathrm{C}$.

Color measurements were performed according to the CIELAB-CIE1976 ( ( $^{*} \mathrm{a}^{*} \mathrm{~b}^{*}$ ) system (Commission Internationale de I'Eclairage-CIE) under the standard D65 illumination with a digital spectrophotometer (VITA Easyshade; Advence Zahnfabrik, Bad Säckingen, Germany) over a white background. Color measurements were performed after staining and after 4 and 8 weeks of treatment. The spectrophotometric data obtained relating to each sample

Table 1. Details of materials used in the study

\begin{tabular}{|c|c|c|c|}
\hline Materials & Manufacturer & Formulations & Application methods \\
\hline Colgate Total & $\begin{array}{l}\text { Colgate Palmolive, } \\
\text { CP, China }\end{array}$ & $\begin{array}{l}\text { Aqua, sodium fluoride, hydrated silica, glycerin, sorbitol, } \\
\text { PVM/MA copolymer, sodium hydroxide, sodium lauryl } \\
\text { sulphate, propylene glycol, triclosan, sodium saccharin }\end{array}$ & $\begin{array}{l}\text { Twice } 2 \text { min, each } \\
\text { day with toothbrush }\end{array}$ \\
\hline $\begin{array}{l}\text { Crest 3D White } \\
\text { toothpaste }\end{array}$ & $\begin{array}{l}\text { Procter \& Gamble, } \\
\text { Cincinnati, } \mathrm{OH}, \mathrm{USA}\end{array}$ & $\begin{array}{l}\text { Sodium fluoride, water, sorbitol, hydrated silica, disodium pyrophosphate, } \\
\text { sodium lauryl sulphate, cellulose gum, sodium hydroxide, sodium } \\
\text { saccharin, carbomer, polyethylene, mica, titanium dioxide, blue } 1 \text { lake }\end{array}$ & $\begin{array}{l}\text { Twice } 2 \mathrm{~min} \text {, each } \\
\text { day with toothbrush }\end{array}$ \\
\hline $\begin{array}{l}\text { Crest 3D White } \\
\text { Multi-Care whitening } \\
\text { mouth rinse }\end{array}$ & $\begin{array}{l}\text { Procter \& Gamble, } \\
\text { Cincinnati, } \mathrm{OH}, \mathrm{USA}\end{array}$ & $\begin{array}{l}\text { Water, 1,5\% hydrogen peroxide, propylene glycol, } \\
\text { sodium hexametaphospate, poloxamer } 407 \text {, sodium } \\
\text { citrate, flavour, sodium saccharin, citric acid }\end{array}$ & $\begin{array}{l}\text { Immersion for twice } \\
1 \text { min, each day } \\
\text { after brushing }\end{array}$ \\
\hline $\begin{array}{l}\text { Crest 3D White strips } \\
\text {-advanced vivid }\end{array}$ & $\begin{array}{l}\text { Procter \& Gamble, } \\
\text { Cincinnati, } \mathrm{OH}, \mathrm{USA}\end{array}$ & $\begin{array}{l}\text { Water, glycerin, } 9.5 \% \text { hydrogen peroxide, carbomer, } \\
\text { sodium hydroxide, sodium saccharin }\end{array}$ & $\begin{array}{l}30 \text { min twice } \\
\text { daily for } 14 \text { days, } \\
\text { after brushing }\end{array}$ \\
\hline Dazzling White & $\begin{array}{l}\text { Grosvenor } \\
\text { Consumer Products, } \\
\text { Ontario, Canada }\end{array}$ & $\begin{array}{l}\text { Purified water, hydrogen peroxide, denatured alcohol, } \\
\text { polyvinyl pyrrolidone, polyethylene glycol }\end{array}$ & $\begin{array}{l}10 \text { min twice } \\
\text { daily for } 28 \text { days, } \\
\text { after brushing }\end{array}$ \\
\hline Opalescence PF & $\begin{array}{c}\text { Ultradent Products } \\
\text { INC, South Jordan, } \\
\text { Utah, USA }\end{array}$ & $\begin{array}{l}\text { Glycerin, water, xylitol, carbamide peroxide, flavor, carbomer, PEG- } \\
300 \text {, sodium hydroxide, potassium nitrate, EDTA, sodium fluoride }\end{array}$ & $4 \mathrm{~h}$ daily for 14 days \\
\hline
\end{tabular}


were recorded as the $L^{*} a^{*} b^{*}$ values. The $L^{*}$ value represents the degree of lightness of a specimen and varies from black (0) to white (100). The $a^{*}$ and $b^{*}$ values represent the degree of red $(+a)-$ green $(-a)$ and yellow $(+b)-$ blue $(-b)$ in the specimens, respectively. The total color difference $(\Delta \mathrm{E})$ was calculated by the following equation: $\Delta \mathrm{E}=\left[\left(\Delta \mathrm{L}^{*}\right)^{2}+\right.$ $\left.\left(\Delta \mathrm{a}^{*}\right)^{2}+\left(\Delta \mathrm{b}^{*}\right)^{2}\right]^{1 / 2}=\left[\left(\mathrm{L}_{1}-\mathrm{L}_{0}\right)^{2}+\left(\mathrm{a}_{1}-\mathrm{a}_{0}\right)^{2}+\left(\mathrm{b}_{1}-\mathrm{b}_{0}\right)^{2}\right]^{1 / 2}$, where the subscripts 0 and 1 denote initial and final values, respectively.

$\Delta \mathrm{E}, \Delta \mathrm{L}, \Delta \mathrm{a}$, and $\Delta \mathrm{b}$ values after 4 and 8 weeks were calculated using color parameters after staining. For $\backslash$ CWS and $\mathrm{OP}$ groups, the first $\Delta \mathrm{E}, \Delta \mathrm{L}, \Delta \mathrm{a}$ and $\Delta \mathrm{b}$ values were calculated after 14 days, and recorded as 4 weeks in Table 2 .

Data after 4 and 8 weeks were analyzed by repeated measures ANOVA. Tukey's test for multiple comparisons was applied at 0.05 level of significance. Statistical analysis was conducted using PASW statistics software 18 (SPSS Inc., Chicago, IL, USA).

\section{Results}

Table 2 shows the means and standard deviations of $\Delta \mathrm{E}, \Delta \mathrm{L}, \Delta \mathrm{a}$, and $\Delta \mathrm{b}$ values from the staining period to 8 weeks of the treatment period. After both 4 and 8 weeks, CWR, CWS, DW and OP groups showed significantly higher whitening effect $(\triangle \mathrm{E})$ than the negative control group $(p<0.05)$. After 4 and 8 weeks, no significant difference was found in tooth whitening $(\Delta \mathrm{E})$ between the CWT and CT groups ( $p>0.05)$. After 4 and 8 weeks, tooth whitening $(\triangle \mathrm{E})$ exhibited by the CWS and DW groups was similar to that exhibited by the positive control group. After 4 and 8 weeks, color change of the CWR group was significantly greater than that of the CWT group. After 8 weeks of treatment, no significant difference in color change was found between the CWS and DW groups. The CWR and DW groups exhibited a significant increase in tooth whitening from 4 to 8 weeks of treatment $(p<0.05)$.

After 4 and 8 weeks, $\Delta \mathrm{L}$ values in the OP group were significantly higher than those in the CT, CWT, and CWR groups, but no significant difference was found in the CWS and DW groups. $\triangle$ a values for the DW group decreased significantly between 4 and 8 weeks of treatment $(p=0.019)$. After 4 and 8 weeks, $\Delta b$ values in the OP group were not significantly different from those in the CWS group but were significantly different from those in other groups. The OP and CWS groups showed a similar reduction in $\Delta b(p>0.05)$.

\section{Discussion}

This study assessed the effectiveness of stain removal with whitening agents containing different concentrations of peroxide and brushing with a tooth paste without bleaching agents for 8 weeks of treatment. The repeated measures ANOVA showed that treatment period and OTC products were important factors for color change. DW and CWS (9.5\% HP) showed similar whitening effect compared with OP $(10 \% \mathrm{CP})$. Thus, the null hypothesis that OTC products had no effect on the whitening of stained teeth was rejected.

In this study, a 24-h tea staining period was preferred because tea has been proven to have a higher capacity to stain teeth than other solutions, such as coffee or chlorhexidine $(14,15)$. In the color space $L^{*} a^{*} b^{*}, L^{*}$ represents lightness and $a^{*}$ and $b^{*}$ show chromaticity coordinates. Rise in the $a^{*}$ and $b^{*}$ directions means that the point moves away from the centre and color saturation rises (11). A positive $\Delta \mathrm{L}$ value after whitening means the teeth tend towards white; negative values of $\Delta a$ and $\Delta b$ indicate that the teeth tend to be less yellow and less red, respectively. The distribution of $\Delta \mathrm{L}, \Delta \mathrm{a}$, and $\Delta \mathrm{b}$ obtained in this study indicated that after both 4 and 8 weeks of whitening, the $L^{*}$ values increased, while the $a^{*}$ and $b^{*}$ values decreased.

Whitening toothpaste used in this study includes abrasives and chemical agents such as pyrophosphate, surfactant, hydrated silica and titanium dioxide.

Table 2. Means and \pm standard deviations of color parameters over the treatment period of 4 and 8 weeks

\begin{tabular}{|c|c|c|c|c|c|c|c|c|}
\hline \multirow{2}{*}{ Groups } & \multicolumn{2}{|c|}{$\Delta \mathrm{E}$} & \multicolumn{2}{|c|}{$\Delta \mathrm{L}$} & \multicolumn{2}{|c|}{$\Delta \mathrm{a}$} & \multicolumn{2}{|c|}{$\Delta \mathrm{b}$} \\
\hline & 4 weeks & 8 weeks & 4 weeks & 8 weeks & 4 weeks & 8 weeks & 4 weeks & 8 weeks \\
\hline CT & $3.44 \pm 1.94 a$ & $2.93 \pm 2.10 \mathrm{a}$ & $0.16 \pm 2.39 a$ & $1.24 \pm 2.22 \mathrm{a}$ & $-1.57 \pm 1.76 a$ & $-1.92 \pm 1.32 \mathrm{a}$ & $-0.34 \pm 2.28 \mathrm{a}$ & $-0.36 \pm 1.06 a$ \\
\hline CWT & $3.12 \pm 1.26 \mathrm{a}$ & $3.85 \pm 1.08 \mathrm{a}$ & $1.10 \pm 0.98 a$ & $2.39 \pm 1.11 \mathrm{a}$ & $-1.96 \pm 0.89 a$ & $-2.14 \pm 0.66 a$ & $-0.13 \pm 2.02 \mathrm{a}$ & $-0.47 \pm 1.72 a$ \\
\hline CWR & $10.46 \pm 1.82 b+$ & $13.41 \pm 1.68 \mathrm{~b}+$ & $6.80 \pm 1.45 b$ & $7.94 \pm 2.32 b$ & $-4.86 \pm 1.61 b$ & $-5.02 \pm 1.50 b$ & $-4.35 \pm 4.65 b+$ & $-5.87 \pm 1.87 b+$ \\
\hline CWS & $19.31 \pm 4.91 \mathrm{c}$ & $20.54 \pm 4.36 c$ & $11.14 \pm 3.63 c$ & $10.89 \pm 3.36 c$ & $-4.85 \pm 2.04 b$ & $-5.14 \pm 1.78 b$ & $-14.84 \pm 3.56 \mathrm{~d}+$ & $-16.51 \pm 3.12 \mathrm{~d}+$ \\
\hline DW & $17.64 \pm 5.77 c+$ & $19.77 \pm 4.32 c+$ & $11.95 \pm 5.20 c$ & $11.75 \pm 3.23 c$ & $-7.63 \pm 3.76 c+$ & $-8.01 \pm 3.50 c+$ & $-11.55 \pm 2.61 c+$ & $-13.44 \pm 2.29 c+$ \\
\hline $\mathrm{OP}$ & $21.32 \pm 3.05 c$ & $21.94 \pm 3.36 c$ & $13.69 \pm 3.19 c$ & $13.08 \pm 3.46 c$ & $-5.69 \pm 1.92 b c$ & $-5.98 \pm 1.81 b$ & $-14.69 \pm 4.06 \mathrm{~d}+$ & $-16.22 \pm 2.97 d+$ \\
\hline
\end{tabular}

For a given time, different superscript lowercase letters indicate statistically significant differences among groups. + : Significant difference between 4 and 8 weeks. 
Pyrophosphates have a strong binding affinity and manage to desorb stain components (16). Hydrated silica has a great cleaning ability and greater ability to remove stains from enamel and dentin compared with other abrasives (9). The results of our study corroborate the findings reported by previous clinical studies and in vitro studies, where whitening toothpaste indicated no significant differences for the removal of extrinsic stain on tooth surface compared with conventional toothpaste $(10,17)$. On the other hand, another study reported that a whitening toothpaste containing hydrogen peroxide presented statistically significant better results for both tooth whitening and prevention of extrinsic tooth stain than the conventional toothpaste (18).

Extrinsic stain on the tooth surface may be removed by means of something abrasive in toothpaste, whereas intrinsic stain can be removed by means of oxidation, based on $\mathrm{HP}$ or $\mathrm{CP}$ that helps lighten the intrinsic discoloration in the tooth. The use of HP or CP in toothpaste is limited (17). Whitening toothpaste tested in this study does not contain peroxide-based whitening agents. Therefore, it can help remove surface stains but does not bleach teeth.

Whitening mouth rinse used in this study presents $\vec{s}$ low concentration of HP and sodium hexametaphosphate that may prevent new stains on the tooth surface (9). These agents work either by bleaching or by removal and prevention of stain (16). A previous study showed that different peroxide-based whitening mouth rinses did not have a bleaching effect on stained teeth (19). However, Torres et al (11) reported that whitening mouth rinses showed similar results to the $10 \% \mathrm{CP}$ in color changes. In the present study, CWR used for 8 weeks according to the manufacturer's recommendations showed significantly lower values than DW, CWS and 10\% CP in tooth whitening $(\triangle \mathrm{E})$ but higher values than $\mathrm{CT}$ and $\mathrm{CWT}$.

Whitening rinses are in contact with the teeth for a short time compared with at-home bleaching, strips and paint-on systems. In addition, it has the bleaching agent in low concentrations and consequently may have less whitening effect. Statistical analysis in this study showed that immersion time in mouth rinse was a significant factor for tooth whitening. Mouth rinses containing HP provide gradual whitening of teeth over a given period of time with continuous use and it is easy to maintain the whitening, but the continuous use of mouth rinse for more time than that recommended by the manufacturer may bring side effects such as mucosa desquamation, pulp sensitivity, ulceration, allergic reactions and burning-mouth sensations (20).

A previous study compared the effectiveness of a paint-on gel (18\% CP), white strips (6\% HP), and fluoride toothpaste and reported significantly greater whitening for white strips compared to the paint-on gel and toothpaste
(21). Dietschi et al (22) reported that tray-based systems $(10 \% \mathrm{CP})$ produced a faster and better bleaching effect compared to a paint-on gel (6\% HP) or strips $(8.1 \% \mathrm{HP})$, regardless of the product and concentration used. Similar findings were noted by Wiegand et al (23), who found that the color change exhibited by $10 \% \mathrm{CP}, 15 \% \mathrm{CP}, 35 \% \mathrm{CP}$, and $35 \% \mathrm{HP}$ was significantly higher than that by $6 \% \mathrm{HP}$ (white strips) in both enamel-dentin and dentin specimens. Contrary to these findings, the paint-on gel and white strips in the present study showed similar results to $10 \%$ $\mathrm{CP}$, an at-home bleaching gel. However, white strips used in this study contained $9.5 \% \mathrm{HP}$, which is nearly equivalent to $28 \% \mathrm{CP}$, and this $\mathrm{HP}$ concentration was higher than concentrations indicated in previous studies. Also, it may be difficult to compare with other studies due to a number of possible factors, including: application protocol differences of whitening agents, staining level of specimens, sample preparation, in vivo and in vitro conditions and so on.

Knowing the percentage of active ingredients in whitening agents would be important in each system, but this information for DW was not available from the manufacturer. DW includes polyvinylpyrrolidone, a watersoluble homopolymer and it can be presented with several applications. This polymer is thought to bind and remove stains in several oral care applications and to prevent stain redeposition and is associated with HP (11).

The 10\% CP was chosen as the positive control group because it has been proven in previous studies to be a safe, effective technique and has been reported in the majority of publications on home bleaching in the last 20 years (24). OTC products are easily applied to teeth and are the least expensive whitening option. The brush-applied gel and white strips provide the comfort of a barrier-free delivery system (25). On the other hand, these products are in direct contact with soft tissues without the supervision of a dentist. Therefore, OTC products can affect all oral tissues with which they have contact.

On the basis of these findings, all groups were effective in tooth whitening in comparison with conventional toothpaste, with the exception of Crest 3D White toothpaste. Crest 3D White mouth rinse showed significantly lower color changes than Dazzling White, Crest 3D White strips and Opalescence PF. Dazzling White and Crest 3D White strips were found to be as effective as Opalescence PF in tooth whitening. Further clinical studies are required to confirm the whitening effect of these products in in vivo conditions.

\section{Resumo}

Este estudo avaliou o efeito branqueador de quarto produtos disponíveis comercialmente em comparação com um gel branqueador contendo 10\% de peróxido de carbamida (PC). Amostras obtidas de incisivos bovinos foram tingidas numa solução de chá e distribuidas aleatoriamente em seis grupos, de acordo com o produto utilizado $(n=10)$ : CT: dentifrício 
convencional (controle negativo); CWT: dentifricio Crest 3D White; CWR: solução para enxague Crest 3D White; CWS: tiras branqueadoras Crest 3D; DW: gel branqueador Dazzling White e OP: Opalescence PF com 10\% de PC (gel branqueador para uso doméstico, controle positivo). Os produtos comerciais e PC a 10\% foram usados de acordo com as instruções dos fabricantes. Foram feitas medidas de cor com o sistema CIELab com espectrofotômetro, imediatamente após o tingimento, e após 4 e 8 semanas do tratamento. Foram calculados os valores de $\Delta \mathrm{E}, \Delta \mathrm{L}, \Delta \mathrm{a}$ e $\Delta \mathrm{b}$. Os dados obtidos foram analisados por ANOVA para medidas repetidas. Foi aplicado o teste de Tukey para comparações múltiplas $(p<0,05)$. Com exceção do Grupo CWS, todos os grupos foram efetivos para o branqueamento dental na comparação com o dentifrício convencional. Não houve diferença significativa no branqueamento dental entre CWT e CT $(p=0,93)$. Os grupos CWS, DW e OP apresentaram mudanças de cor significativamente maiores que o grupo CWR. Os grupos DW e CWS produziram branqueamento similar a $\mathrm{OP}$.

\section{References}

1. Joiner A. Tooth colour: a review of the literature. J Dent 2004;32Suppl1:3-12.

2. Lima FG, Rotta TA, Penso S, Meireles SS, Demarco FF. In vitro evaluation of the whitening effect of mouth rinses containing hydrogen peroxide. Braz Oral Res 2012;26:269-274.

3. Watts A, Addy M. Tooth discolouration and staining: a review of the literature. Br Dent J 2001;190:309-316.

4. Nathoo SA. The chemistry and mechanisms of extrinsic and intrinsic discoloration. J Am Dent Assoc 1997;128Suppl:6S-10S.

5. Addy M, Moran J, Newcombe R, Warren P. The comparative tea staining potential of phenolic, chlorhexidine and anti-adhesive mouth rinses. J Clin Periodontol 1995;22:923-928.

6. Sulieman M, Addy $M$, Rees JS. Development and evaluation of a method in vitro to study the effectiveness of tooth bleaching. J Dent 2003;31:415-422.

7. Braun A, Jepsen $S$, Krause F. Spectrophotometric and visual evaluation of vital tooth bleaching employing different carbamide peroxide concentrations. Dent Mater 2007;23:165-169.

8. Joiner A. The bleaching of teeth: a review of the literature. J Dent 2006;34:412-419.

9. Demarco FF, Meireles SS, Masotti AS. Over-the-counter whitening agents: a concise review. Braz Oral Res 2009;23:64-70.

10. Lima DA, Silva AL, Aguiar FH, Liporoni PC, Munin E, Ambrosano GM, et al.. In vitro assessment of the effectiveness of whitening dentifrices for the removal of extrinsic tooth stains. Braz Oral Res 2008;22:106-111.
11. Torres CR, Perote LC, Gutierrez NC, Pucci CR, Borges AB. Efficacy of mouth rinses and toothpaste on tooth whitening. Oper Dent 2013;38:57-62.

12. McCracken GI, Janssen J, Swan M, Steen N, de Jager M, Heasman PA. Effect of brushing force and time on plaque removal using a powered toothbrush. J Clin Periodontol 2003;30:409-413.

13. Ashcroft AT, Cox TF, Joiner A, Laucello M, Philpotts CJ, Spradbery PS, et al.. Evaluation of a new silica whitening toothpaste containing blue covarine on the colour of anterior restoration materials in vitro. J Dent 2008;36:S26-S31.

14. Leard A, Addy M. The propensity of different brands of tea and coffee to cause staining associated with chlorhexidine. J Clin Periodontol 1997;24:115-118.

15. Addy M, Moran J. The formation of stain on acrylic surfaces by the interaction of cationic antiseptic mouthwashes and tea. J Biomed Mater Res 1984;18:631-641.

16. Joiner A. Whitening toothpastes: a review of the literature. J Dent 2010;38:e17-e24.

17. Horn BA, Bittencourt BF, Gomes OM, Farhat PA. Clinical evaluation of the whitening effect of over-the-counter dentifrices on vital teeth. Braz Dent J 2014;25:203-206.

18. Sharma N, Galustians HJ, Qaqish J, Rustogi K, Zhang YP, Petrone ME, et al.. Comparative tooth whitening and extrinsic tooth stain prevention efficacy of a new dentifrice and a commercially available tooth whitening dentifrice: six-week clinical trial. J Clin Dent 2004;15:52-57.

19. Potgieter $E_{1}$ Grobler SR. Whitening efficacy of three over-the-counter oral rinses. SADJ 2011;66:128-131.

20. Goldberg M, Grootveld M, Lynch E. Undesirable and adverse effects of tooth-whitening products: a review. Clin Oral Investig 2010;14:1-10.

21. Lo EC, Wong AH, McGrath $\mathrm{C}$. A randomized controlled trial of home tooth-whitening products. Am J Dent 2007;20:315-318.

22. Dietschi D, Benbachir N, Krejci I. In vitro colorimetric evaluation of the efficacy of home bleaching and over-the-counter bleaching products. Quintessence Int 2010;41:505-516.

23. Wiegand A, Vollmer D, Foitzik M, Attin R, Attin T. Efficacy of different whitening modalities on bovine enamel and dentin. Clin Oral Investig 2005;9:91-97.

24. Kihn PW. Vital tooth whitening. Dent Clin North Am 2007;51:319-331

25. Kishta-Derani M, Neiva G, Yaman P, Dennison J. In vitro evaluation of tooth-color change using four paint-on tooth whiteners. Oper Dent 2007;32:394-398. 